\title{
ЭМОЦИОНАЛЬНЫЕ ОСОБЕННОСТИ ПЕДАГОГОВ В УСЛОВИЯХ ДИСТАНЦИОННОЙ РАБОТЫ В ПЕРИОД ПАНДЕМИИ
}

\author{
Оганнисян Л.А. (Южный Федеральный Университет, \\ Ростов-на-Дону, Россия) \\ laogannisyan@sfedu.ru

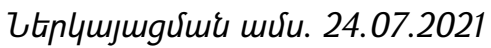 \\ 9pupunuर्uाध шर्रu. 10.08.2021

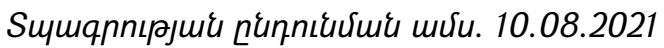

Профессиональная деятельность педагога является одной из самых стрессогенных. Переход на дистанционную фрорму работу, в связи с ограничениями в период пандемии, породил у педагогов особое эмоциональное напряжение, вызванное рядом факторов. В сложившихся обстоятельствах эмоциональная сфера педагога, влияние которой на эффрективность достижения образовательных задач доказано многочисленными исследованиями, вновь оказывается в центре внимания.

В связи с вышесказанной целью нашего исследования является изучение особенностей эмоциональной сферы педагогов в условиях дистанционной работы в период пандемии. Методики исследования: 16факторный личностный опросник Р. Кетелла (блок эмоционально-волевых качеств; адаптация А.Н. Капустиной), «Шкала диффреренциальных эмоций» (К. Изард, адаптация А.Б. Леоновой), методы математической статистики. Выборка: педагоги учреждений СПО г. Ростова-на-Дону, в количестве 53 человек (от 30 до 45 лет).

В результате исследования было доказано, что педагогов в период дистанционной работы отличает эмоциональная неустойчивость, повышенная тревожность, неуверенность в себе, сомнения и мнительность, низкая саморегуляция, низкий контроль эмоций и поведения, стрессоустойчивость, а также более высокая степень выраженности «страха» и «стыда».

Ключевые слова: педагоги, эмоции, эмочиональные особенности педагогов, дистанционное образование, пандемия.

DOI: https://doi.org/10.46991/SBMP/2021.4.2.251

Изучение различных аспектов проблемы эмоций не теряет своей актуальности на протяжении десятилетий, т.к. эмоции сопровождают нас постоянно как в повседневной жизни, так и в профессиональной деятельности. Эмоции непосредственно связаны с мотивацией и волевой сорерой, детерминируют выбор человека, его социальное поведение, мнение о ситуации, других людях, положении в стране 
В отечественной и зарубежной психологии существует множество различных взглядов на природу эмоций, их виды и функции: П.В. Симонов, П.К. Анохин, А.Н. Леонтьев, С.Л. Рубинштейн, Б.И. Додонов, Ч. Дарвин, У. Джеймс, Г. Ланге, У. МакДауголл, Ж.-П. Сартра, Л. Фестингер, К.Э. Изард и многие другие. Несмотря на то, что проблемой эмоций отечественные и зарубежные психологи занимаются достаточно давно, единого мнения по вопросам классификации, функций и даже самого понятия эмоций так и недостигнуто. На данном этапе развития психологической и педагогической науки существует большое количество работ, посвященных исследованию различных аспектов эмоционально-волевой сферы человека. Особенно популярными становятся работы, посвященные изучению взаимосвязи эмоций и других психических процессов (Густяков Н.А., Ворсобин В.Н., Жидкий В.Н., Тихомиров О.К., Шехтер С и др). В то же время, практически не было уделено внимания вопросам динамики эмоций, и только в последние десятилетия ученые заинтересовались этим аспектом проблемы.

Специфика педагогической деятельности, которая заключается в первую очередь в том, что педагог сам, как человек, как личность, является главным средством своего труда, обуславливает пристальное отношение психологов исследователей к эмоциональной составляющей личности педагога. Эмоциональность является одной из основ педагогической деятельности, при этом она включает в себя широкий спектр эмоций. Многие авторы указывают, что эмоциональная сорера педагога будет адаптироваться к условиям профессиональной деятельности нормально, в том случае, если выполнены все обязательные условия возникновения положительных эмоций. В данном случае педагоги будут эмоционально спокойны, сосредоточены, заинтересованы, эмпатийны и пр.

В исследованиях эмоциональности педагогов нашло свое отражение и изучение эмоционального интеллекта, который в значительной мере помогает упорядочить понимание субъектом своей афффективно-эмоциональной сферы (Н.П. Александрова, И.С. Якиманская и др.). Л.Б. Симонова отмечает, что эмоциональный интеллект педагога можно рассматривать как инструмент дальнейшей гуманизации системы образования, реализации индивидуального подхода к обучению и развитию личности [6].

Современный этап развития общества привел к изменениям и в сорере образования. Дистанционное обучение стало не одним возможных вариантов освоения учебных планов, а стало естественным процессом в условиях пандемии, сохраняя свои лидирующие позиции и на сегодняшний день. Во всем мире применение дистанционного обучения становится нормой, разрабатываются и применяются новые методы, техники, технологии работы. Современные технологии дистанционной работы позволяют педагогам решать 
ряд профессиональных задач, в число которых входят создание единого образовательного пространства, формирование у обучающихся активной самостоятельной позиции познающего, развитие критического мышления.

Х.М. Ханапиева выделяет несколько основных целей дистанционного обучения: «1) повышение квалификации педагогических кадров; 2) подготовка и переподготовка кадров; 3) углубленное изучение тем, разделов из изучаемых дисциплин; 4) ликвидация пробелов в знаниях, умениях, навыках обучаемых по определенным дисциплинам; 5) базовый курс учебной программы для учащихся, не имеющих возможности по разным причинам посещать очные учебные занятия; 6) дополнительное образование по интересам» [7, с.80].

При этом, по мнению автора, в основе дистанционного обучения лежат два базовых принципа. К первому относится принцип свободного доступа, ко второму - минимальный личный контакт педагога и обучающегося, при доминировании самостоятельной работы.Также Х.М. Ханапиева указывает, что несмотря на профессионализм педагогов, на их владение разнообразными техниками и методиками преподавания своего предмета, переход на дистанционные фрормы обучения вызвал у многих значительные трудности. Особые затруднения вызывают отсутствие «живой» аудитории и необходимость взаимодействовать с неким дистанционным сообществом, которое не всегда возможно визуализировать. Дистанционное обучение коренным образом отличается от традиционных форм обучения. При рассмотрении дистанционного обучения как деятельности, опосредованной компьютерными технологиями, надо отметить, что внедрение компьютерных технологий в нашу жизнь имеет ряд психологических последствий. Специалисты выделяют следующие психологические феномены, связанные с освоением человеком новых инорормационных технологий: 1. Персонификацию, «одушевление» компьютера, когда компьютер воспринимается как живой организм; 2. потребность в «общении» с компьютером и особенности такого общения; 3. различные формы компьютерной тревожности [1].

Некоторые авторы доказывают, что компьютерные технологии вторгаясь в наш внутренний мир, вызывают разнообразные нарушения, в первую очередь, в эмоциональной сорере [5].

Так, А.В. Минаков, освещая проблемы информатизации, приводит негативные примеры - побочные эффректы применения информационных технологий, с которыми сталкиваются психологи и психотерапевты современности. К К ним относятся: «технострессы, компьютерофоббии, зависимость от компьютерных игр (индивидуальных, групповых, ролевых), Интернет - зависимость, хакерство, сужение круга интересов, аутизация, трансформация идентичности, неразвитость социального интеллекта, обеднение социального компонента общения и другие» [4, с.57]. Многочисленные 
исследования доказывают, что успешность педагогической деятельности, в первую очередь зависит от личности самого педагога и его эмоционального состояния. При этом эмоциональная сфера педагогов претерпевает регулярные изменения и различные деформации под воздействием разнообразных субъективных и объективных фракторов. И эти изменения наблюдаются у педагогов с первого и до последнего дня выполнения профессиональной деятельности (Н.А. Аминов, В.В. Бойко, Ю.С. Жуков, Э.Ф. Зеер, Е. Махер, А.К. Осницкий, А.С. Шафранова, Т.В. Форманюк, Х.Дж. Фрейденберг и др.).

Переход всех образовательных организаций в сжатые сроки на дистанционную фрорму работу стал одним из ключевых стрессовых фракторов как для обучающихся, так и для педагогического состава. Необходимость изменять методику преподавания и структуру занятия, менять фронды оценочных средств, использование новых информационно-коммуникационных технологий, новых платорорм для организации занятия привело к эмоциональному истощению, нервному перенапряжению, подавленности, что влечет за собой дезорганизующий эффрект. Поскольку в XX столетии в целом, и в последние несколько лет, в частности, проблема дистанционного обучения заявила о себе особенно остро, есть необходимость проведения и осуществления психологических исследований в этом направлении. В связи с этим, целью нашего исследования является изучение особенностей эмоциональной сореры педагогов в условиях дистанционной работы в период пандемии. Для достижения поставленной цели были использованы следующие методики: 16-факторный личностный опросник Р. Кетелла (блок эмоциональноволевых качеств; адаптация А.Н. Капустиной), «Шкала дифференциальных эмоций» (К. Изард, адаптация А.Б. Леоновой), методы математической статистики (описательная статистика, Т-критерий Вилкоксона). В исследовании приняли участие педагоги учреждений СПО г. Ростова-на-Дону, в количестве 53 человек (от 30 до 45 лет). Первичная диагностика была проведена в 2018 году, когда образовательный процесс проходил в контактной форме. Повторная диагностика была проведена в 2020 году в период перехода всех образовательных учреждений на дистанционную фрорму работы. Повторная диагностика проводилась в дистанционном фрормате, с использованием приложения MS Forms. Нами были высказаны предположения, что у педагогов В период дистанционной работы будут наблюдаться изменения в эмоционально-волевой сфере, а также, что у педагогов в период контактной и дистанционной работы будут доминировать разные фундаментальные эмоции.

В процессе исследования выявлено, что у педагогов в период дистанционной работы низкими показателями представлены фракторы «С» (эмоциональная устойчивость), «Q3» (самоконтроль), «Q4» (напряженность), 
«L» (доверчивость) и «G» (организованность) фрактору. И высокими факторы «O» (тревожность), «F» (сдержанность) и «l» (чувствительность).

Педагоги в период контактной работы демонстрировали высокие показатели по факторам " $\mathrm{C}$ " (эмоциональная устойчивость), « $\mathrm{Q}_{3}$ " (самоконтроль), «Q $\mathrm{Q}_{4} »$ (напряженность), «L» (доверчивость) и «G» (организованность) и очень низкие показатели по фракторам "О» (тревожность), «F» (сдержанность) им «l» (чувствительность) (Рисунок 1).

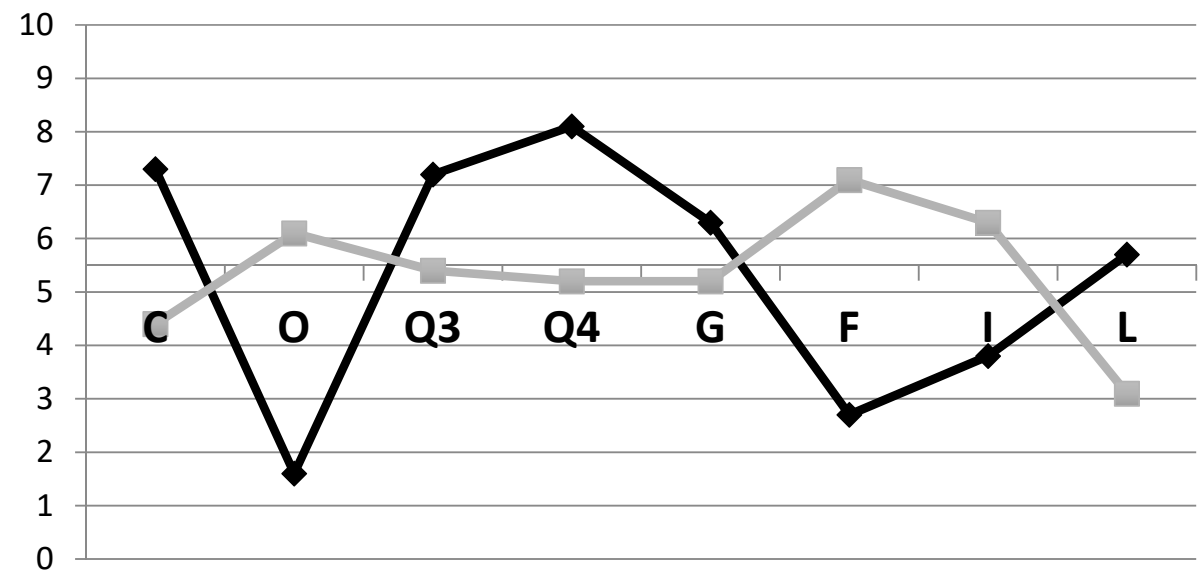

- контактная - дистантная

Рисунок 1. Показатели выраженности эмоционально-волевых качеств личности педагога

Следовательно, педагогам в период дистанционной работы свойственны эмоциональная неустойчивость, импульсивность, переменчивость в настроениях, неустойчивость в интересах, склонность к непостоянству, подверженность влиянию чувств, случая и обстоятельств, тревожность, обеспокоенность. Для них характерна низкая дисциплинированность, зависимость от настроений, неумение контролировать свои эмоции и поведение, невысокий уровень мотивации достижения, стремление возложить ответственность за ошибки на окружающих, раздражительность. В тоже время, мы можем предположить, что для этих же педагогов в период контактной работы были характерны напряженность, требовательность к себе, уверенность в себе и своих способностях, невозмутимость, настойчивость, добросовестность, независимость, агрессивность, упрямство, неторопливый, сдержанный, сильный, независимый, адаптирующийся.

Статистическая обработка данных с помощью Т-критерия Вилкоксона выявила достоверно значимые изменения в степени выраженности 
эмоционально-волевых качествах личности педагогов в условиях контактной и дистанционной работы по таким факторам, как «эмоциональная нестабильность - эмоциональная стабильность» (C; $\mathrm{T}=451,034, \mathrm{p}=0,010)$, «сдержанность-экспрессивность» (F; $\mathrm{T}=259,347, \quad \mathrm{p}=0,000)$, «жестокостьчувствительность» $(\mathrm{I} ; \mathrm{T}=450,434, \mathrm{p}=0,010)$, «спокойствие - тревожность» (0; $\mathrm{T}=267,545, \mathrm{p}=0,000)$ и «расслабленность - напряженность» (Q4; T=288,883, $\mathrm{p}=0,003)$. Таким образом, педагогов в период дистанционной работы отличает эмоциональная неустойчивость, пластичность нервной системы, повышенная тревожность, неуверенность в себе, сомнения и мнительность, низкая саморегуляция, низкий контроль эмоций и поведения. Для них свойственны некоторая слабость, зависимость, слабо выраженная самостоятельность, приспособляемость, отсутствие стремления к конкуренции.

Нами также были выявлены особенности выраженности фундаментальных эмоций у педагогов в период контактной и дистанционной работы. Так, в период дистанционной работы у педагогов наиболее выраженной эмоцией является «интерес», но второе место, в отличие от более ранних замеров, занимает «гнев». «Радость» и "удивление» располагаются на третьем и четвертом местах соответственно. Пятую позицию разделили между собой «отвращение» и «презрение». За ними следуют «вина, «горе», «стыд» и «страх».

В период контактной работы для педагогов была характерна высокая степень выраженности «интереса» и «радости». На второй и третьей позиции располагались «вина» и «стыд». Далее следовали «удивление», «горе» и «гнев». А на последних трех местах - «страх», «отвращение» и «презрение» (Рисунок 2).

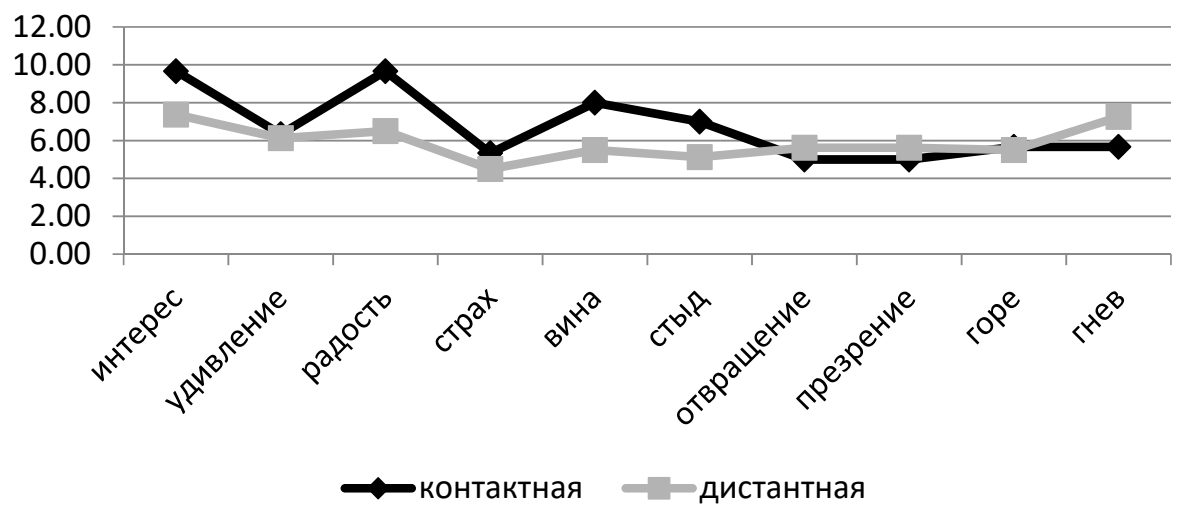

\section{Рисунок 2. Показатели выраженности фрундаментальных эмоций педагогов}

Следовательно, можно предположить, что доминирующими эмоциями в жизни педагогов в период дистанционной работы являются интерес и гнев. В 
тоже время страх, стыд, горе и вина им практически не свойственны. В период контактной работы у педагогов были более выражены склонность к переживанию интереса и радости, в то время как презрение, отвращение, страх, гнев и горе им были свойственны в меньшей степени.

Однако статистически достоверные различия выявлены только по четырем фрундаментальным эмоциям: “радость» ( $T=364,656, p=0,008)$, «стыд» ( $T=271,473, p=0,003)$, «гнев» ( $T=270,475, p=0,003)$ и «вина» ( $T=298,994$, $\mathrm{p}=0,004)$.Таким образом, можно сказать, что у педагогов как в период контактной работы, так и в период дистанционной работы ведущей эмоцией является «интерес», что объясняется спецификой профессии и развитыми профессионально-важными качествами педагогов, т.к. данная эмоция способствует развитию навыков и умений, приобретению знаний, мотивирует постоянное саморазвитие. У педагогов преобладает желание исследовать, расширить опыт путем включения и подойти по-новому к лицу или объекту, возбудившему интерес.

В период дистанционной работы отличительной чертой педагогов является ярко выраженное преобладание эмоции «гнева», возникающий в результате чувства фризического или психологического препятствия тому, что педагог очень хочет сделать, либо в ситуации личного оскорбления, повседневной фррустрации, прерывания ситуаций интереса или радости, в случае обмана, принуждения сделать что-то против желания. Также общими чертами эмоциональной сореры педагогов в оба периода является средняя и низкая степень выраженности таких эмоций как: "удивление», «страх», «отвращение», «презрение» и «горе», что говорит о возникновении данных эмоциональных переживаний только в ответ на соответствующие ситуации, например, реакция на потерю, утрату, рассогласование жизненных позиций, взглядов и поведения субъекта с представлениями педагогов, в ситуациях реальной или воображаемой опасности. Таким образом, в результате нашего исследования было доказано, что педагогов в период дистанционной работы отличает эмоциональная неустойчивость, пластичность нервной системы, повышенная тревожность, неуверенность в себе, сомнения и мнительность, низкая саморегуляция, низкий контроль эмоций и поведения, стрессоустойчивость, в то время, как во время контактной работы эти же педагоги демонстрировали эмоциональную устойчивость, уверенность в себе и в своих силах, спокойное адекватное восприятие действительности, умение контролировать свои эмоции и поведение, стрессоустойчивость.

Нами было выявлено, что доминирующая эмоция у педагогов и в период контактной работы, и в период дистанционного обучения - интерес, что, на наш взгляд, объясняется высоким уровнем развития профессионально-важных качеств педагогов. В тоже время педагогов в период дистанционной работы 
отличает более высокая степень выраженности «страха» и «стыда», а отличительной чертой педагогов в период контактной работы является ярко выраженное преобладание эмоции «гнева.

\section{Литература}

1. Бондарькова А.М. Педагогическое управление профессиональным саморазвитием студентов технических вузов, обучающихся дистанционно: Дис. канд. пед. наук. М., 2010 - 138с.

2. Кутковой Н.А., Стефаненко Т.Г. Понятие эмоций в социальной психологии XXI века: основные подходы // Психологические исследования. 2014, T.7, №33. - C.7. URL: http://psystudy.ru (дата обращения: 11.10.2020).

3. Лотош Л.С. Особенности эмоционально-личностной сфреры учителей в системе дополнительного образования школьников. Дисс ... канд. псих. наук Ярославль, 2006 - 148 с.

4. Минаков А.В. Гудошникова Ю.Ю. Психологические особенности лиц, склонных к Интернет-зависимости // Воронежское отделение РПО. Режим доступа: http://www. vspu. ac. ru/ imago/publ5m. htm. - 2010.

5. Моросанова В.И. Индивидуальная саморегуляция и характер человека // Вопросы психологии, 2007, №3. - с. 59-68.

6. Почтарева Е.Ю. Эмоциональный интеллект как составляющая непрерывного образования педагога // Научное обеспечение системы повышения квалификации кадров. 2012, №2. - с.75-81

7. Ханапиева Х.М. Особенности работы преподавателя при дистанционной форме обучения//Известия ДГПУ. Психологопедагогические науки. 2017, №2. URL: https://cyberleninka.ru/article/n/osobennosti-raboty-prepodavatelya-pridistantsionnoy-forme-obucheniya (дата обращения: 05.05.2020)

8. Шабанова Т.Л. Изучение особенностей эмоциональной сореры педагогов как компонентов эмоциональной устойчивости в профессиональной деятельности // Наука и школа. 2011, №2. URL: https://cyberleninka.ru/article/n/izuchenie-osobennostey-emotsionalnoysfery-pedagogov-kak-komponentov-emotsionalnoy-ustoychivosti-vprofessionalnoy-deyatelnosti (дата обращения: 09.07.2020). 


\title{
EMOTIONAL FEATURES OF TEACHERS UNDER REMOTE WORK DURING PANDEMIC PERIOD
}

\author{
Ogannisyan L. A. (Southern Federal University, Rostov-on-Don, Russia)
}

The professional activity of a teacher is one of the most stressful. The transition to a remote form of work, due to the restrictions during the pandemic, gave rise to special emotional stress among teachers, caused by a number of factors. In the current circumstances, the emotional sphere of the teacher, the influence of which on the effectiveness of achieving educational objectives has been proven by numerous studies, is again in the spotlight.

In connection with the above, the purpose of our study is to study the characteristics of the emotional sphere of teachers in the conditions of remote work during a pandemic. Research methods: R. Ketell's 16-factor personality questionnaire (block of emotional-volitional qualities; adaptation by AN Kapustina), "Scale of differential emotions" (K. Izard, adaptation by AB Leonova), methods of mathematical statistics. Sample: teachers of secondary vocational schools in Rostovon-Don, in the amount of 53 people (from 30 to 45 years old). As a result of the study, it was proved that teachers during the period of distance work are distinguished by emotional instability, increased anxiety, self-doubt, doubts and suspiciousness, low self-regulation, low control of emotions and behavior, stress resistance, as well as a higher degree of expression of "fear" and "shame ".

Keywords: teachers, emotions, emotional characteristics of teachers, distance education. 